\title{
DIREITO INTERNACIONAL FRAGMENTADO E PROTEÇÃO AOS DIREITOS HUMANOS: ALGUMAS REPERCUSSÕES PARA O DESENVOLVIMENTO DOS ESTADOS
}

\author{
FRAGMENTED INTERNATIONAL LAW AND THE PROTECTION OF HUMAN RIGHTS: \\ SOME OUTCOMES TO THE DEVELOPMENT OF THE STATES
}

\author{
Henrique Weil Afonso* \\ José Luiz Quadros de Magalhães** \\ Data de recebimento: 22/04/2011 \\ Data de aprovação: 06/05/2012
}

\section{RESUMO}

O presente artigo pretende investigar aspectos do processo de fragmentação do Direito Internacional e seus desdobramentos para os Estados nacionais. A marca essencial desse processo é a consolidação de regimes auto-suficientes, que se afastam das normas gerais de Direito Internacional, de modo a comprometer sua unidade. Tais regimes buscam tutelar disciplinas de elevada especificidade técnica, exigindo do operador legal o desenvolvimento de mecanismos capazes de compreender as peculiaridades das relações internacionais. Racionalidades contrastantes e muitas vezes conflituosas competem pelo domínio do espaço normativo, o que acaba por influir de modo decisivo na realização de políticas públicas - um caso de política de saúde será examinado - por parte dos poderes locais.

\section{PALAVRAS-CHAVE}

Direito Internacional; Fragmentação e Unidade; Políticas Públicas.

\footnotetext{
- Graduado em Direito pela Universidade Federal de Juiz de Fora. Mestre e Doutorando em Direito Público Internacional pela PUC Minas. Professor Instituto Vianna Jr (Juiz de Fora, MG).

E-mail: henrique_weil@yahoo.com.br
}

\footnotetext{
** Mestre e Doutor em Direito pela Universidade Federal de Minas Gerais. Professor Adjunto da UFMG, professor Titular da PUC Minas na graduação, mestrado e doutorado e professor da Faculdade do Sul Minas.

E-mail: ceede@uol.com.br
} 


\section{ABSTRACT}

The present essay intends to investigate certain aspects of the process of fragmentation of International Law and its relations to Nation-States. The most important mark of this process is the consolidation of the self-contained regimes, which deviates from general norms of International Law, in a way that threatens its unity. Such regimes seek to regulate disciplines of particularly high degrees of technical expertise. It demands legal lawyers to develop mechanisms capable of understanding the peculiarities of international relations. Different and at times contrasting rationalities compete for the very same normative space, which influence in a decisive manner the realization of public policies - a case of health policy is examined - by local powers.

\section{KEYWORDS}

International Law; Fragmentation and Unity; Public Policy. 


\section{INTRODUÇÃO}

O fenômeno da globalização e a diversificação das relações internacionais imprimem variados desafios à ordem jurídica internacional. Novos sujeitos de Direito Internacional lutam por reconhecimento e por um papel mais ativo na consecução dos objetivos da agenda internacionalista: a lógica mercadológica, o liberalismo econômico e o ceticismo acerca da disposição dos Estados em reforçarem a aplicação das normas do Direito Internacional reduzem o potencial transformador do mesmo, que se modifica e se redefine aos moldes das forças atuantes no cenário mundial.

Muitos são os elementos que retiram o caráter unitário do Direito Internacional - que se fragmenta -, devendo este ser analisado sob óticas mais condizentes com as estruturas e os discursos presentes nas diversas racionalidades que competem pelos mesmos espaços normativos no plano global. Tais disputas, em seu turno, incidem de forma direta na autonomia dos Estados relativa ao planejamento de políticas públicas - em especial, políticas de saúde pública -, cuja qualidade e eficiência consistem na realização de Direitos das pessoas.

\section{A UNIDADE DO DIREITO INTERNACIONAL}

Surgido no momento de consolidação ${ }^{1}$ do moderno Estado-nação na Europa do século XVII, o sistema jurídico internacional teve como função principal a regulação das relações entre os mais importantes sujeitos de direito em nível global ${ }^{2}$.

É interessante notar que o predomínio do Estado-nação como o legítimo ator em nível global deveu-se ao desenvolvimento de algumas importantes formulações teóricas. Primeiramente, o conceito de soberania estatal inaugurou as noções fundamentais do monopólio do uso da força por parte das instituições estatais e o império do Direito no âmbito doméstico. Já a partir da noção de soberania estatal, visualizouse outro importante marco teórico para o plano jurídico internacional: a idéia de igualdade soberana entre os Estados ${ }^{3}$.

A ampla aceitação destes conceitos pelos Estados republicanos do século XVIII

\footnotetext{
${ }^{1}$ A este respeito, deve-se enfatizar que a construção do Estado-nação como ente abstrato deu-se de forma desigual ao redor do mundo, tendo sua consolidação ocorrida primeiramente na Europa - Portugal, Espanha, França e Inglaterra, em especial - a partir do domínio do poder da nobreza sobre os senhores feudais, para, em um momento posterior, afirmar-se perante o poder do Império e da Igreja do século XVII. CREVELD, Martin van. Ascensão e declínio do Estado, p. 210).

${ }^{2}$ Martin Van Creveld. Ascensão e declínio do Estado, São Paulo: Martins Fontes.

${ }^{3}$ Gerson de Britto Mello Boson. Direito internacional público: o Estado em direito das gentes. BH: Del Rey, p. 97.
} 
foi, segundo Martin Van Creveld, essencial para o projeto de enfraquecimento do poder monárquico e conseqüente consolidação do Estado-nação moderno. O princípio da não-intervenção em assuntos internos dos Estados - hoje positivado na Carta da Organização das Nações Unidas - seria, nesse diapasão, desdobramento e corolário da igualdade soberana entre os Estados.

Com efeito, o mesmo processo histórico que caracterizou a formação do postulado da soberania estatal marcou também a consolidação de um "Estado de Natureza" em nível internacional. De um lado, o império do Direito no âmbito doméstico resultou da emergência do Estado como paradigma de organização social. De outro lado, a materialização de um mundo dividido em entidades soberanas culminou na legitimação do recurso à força armada como extensão da atividade política estatal e, não menos importante, na inviabilidade de formulação de uma entidade capaz de conferir ordem ao sistema global. ${ }^{4}$

Destarte, o século XIX marca a consolidação de uma estrutura conceitual básica de Estado de Direito - influência da Revolução Francesa e da promulgação da Constituição dos Estados Unidos da América -, e sua gradual inserção no modelo de Estado-nação moderno produziu um Direito Internacional de co-ordenação: ao Direito Internacional competia, fundamentalmente, viabilizar as relações entre Estados independentes e autônomos ${ }^{5}$, tomando a forma de um Direito meramente procedimental e que estaria a serviço dos Estados soberanos. Nesse contexto, a guerra seria, conforme prescreveu Carl Von Clausewitz, “[...] a realização da política por outros meios". ${ }^{6}$.

Marcado primariamente pela unidade e sistematização, era, por assim dizer, um Direito voltado para a defesa do absolutismo nacional:

Fundado na soberania suprema do Estado, pela qual qualquer idéia de autodeterminação e interferência externa em seus assuntos internos era uma aberração, suas características centrais eram que o uso da força armada como forma de realização de políticas seria legítimo, e que o estado de guerra entre dois ou mais países, com seu impacto em outros Estados tidos como 'neutros', era a reconhecida condição das relações internacionais e era regulada pelo Direito. (tradução nossa). ${ }^{8}$

\footnotetext{
${ }^{4}$ Ferrajoli, 2007, p.50.

${ }^{5}$ Sh Rosenne. Recueil des Cours. Martinus Nijhoff Publishers, 2002.

${ }^{6}$ Carl Von Clausewitz. On War. London: Penguin Books, 1982, p. 88 (tradução nossa)

7 "[...] the realization of politics by other means."

8 "Founded on the supreme sovereignty of the State in which any idea of self-determination and outside interference in its internal affairs was anathema, its central features were that the use of armed force to further
} 


\section{A FRAGMENTAÇÃO DA ORDEM JURÍDICA GLOBAL}

A função coordenativa do Direito Internacional em face dos Estados foi objeto de profundas alterações no decorrer da segunda metade do século XX. A este respeito, importantes referenciais tomam forma: a criação da Organização das Nações Unidas (ONU) no cenário resultante da Segunda Guerra Mundial, assim como os desafios de uma realidade internacional cambiante, representaram a emergência de um novo momento para o Direito Internacional. ${ }^{9}$

Para além da coordenação das relações entre os Estados, ao Direito Internacional são incorporados uma série de objetivos cuja realização integra uma nova agenda para a sociedade internacional. $\mathrm{O}$ sistema jurídico internacional passa a reconhecer $\mathrm{o}$ importante papel desempenhado pelas organizações intergovernamentais e, em certa medida, pelo ser humano como sujeitos de Direito em nível global. A restrição das hipóteses de recurso ao uso da força $\operatorname{armada}^{10}$, o amplo respaldo estatal à ONU e a codificação de um conjunto de direitos referente a todos os seres humanos são elementos que muito bem ilustram os novos desafios do Direito Internacional.

$\mathrm{O}$ processo de internacionalização ${ }^{11}$ dos Direitos Humanos assume status de verdadeira cruzada ${ }^{12}$. Por conseguinte, representa tarefa de todos os Estados, com o auxílio das organizações internacionais, assegurarem a realização desses direitos ao maior número de pessoas:

O moderno Direito Internacional dos Direitos Humanos é um fenômeno do pósguerra. Seu desenvolvimento pode ser atribuído às monstruosas violações de Direitos Humanos da era Hitler e à crença de que parte destas violações poderiam

national policy was legitimate, and that a state of war between two of more countries, with its impact on other States designated as "neutral", was a recognized condition of international relations and was one regulated by the law." Rosenne, Sh. Recueil des Cours. Tome 291 de La collection. The Hague: Martinus Nijhoff Publishers, p. 25.

${ }_{9}^{9}$ Antonio Augusto Cançado Trindade. A humanização do direito internacional. BH: Del Rey, 2006, p.82.

${ }^{10}$ Michael Byers. A lei da guerra: direito internacional e conflito armado. RJ: Ed. Record, 2007, p. 30.

${ }^{11}$ Dentre os tratados internacionais de Direitos Humanos de maior relevância, merecem destaque: o Pacto Internacional de Direitos Civis e Políticos, que, até 2003, contava com 149 Estados-partes; o Pacto Internacional dos Direitos Econômicos, Sociais e Culturais, que conta com 149 Estados-partes; a Convenção contra a Tortura, que conta com 132 Estados-partes; a Convenção sobre a Eliminação da Discriminação Racial, que conta com 167 Estados-partes; a Convenção sobre a Eliminação da Discriminação contra a Mulher, que conta com 170 Estados-partes; e a Convenção sobre os Direitos da Criança, que apresenta a mais ampla adesão, contanto com 191 Estados-partes.

${ }^{12}$ Antonio Augusto Cançado Trindade. A humanização do direito internacional. BH: Del Rey, 2006, p. 18. 
ser prevenidas se um efetivo sistema de proteção internacional dos Direitos $\mathrm{Hu}-$ manos existisse..$^{13}$

Desse modo, o Direito Internacional contemporâneo regula uma gama muito ampla de temas - merecendo atenção especial os Direitos Humanos, o comércio internacional e o meio ambiente. Para tanto, novas fontes produtoras de normas ganham força, regulando matérias de elevada complexidade e especificidade, dando origem a regimes próprios - fragmentados - e que vêm se tornando cada vez mais independentes das normas de Direito Internacional geral:

[...] constata-se a criação de novos regimes 'às margens' das normas de Direito Internacional geral, isto é, regimes que repudiam a estrita obediência ao texto legal, preconizando a realização dos objetivos mais específicos. Nesta seara, Martti Koskenniemi [...] aponta para os tratados de Direitos Humanos. ${ }^{14}$

A fragmentação da ordem jurídica global consiste na emergência de regimes auto-suficientes cujo objetivo é regular disciplinas de elevada especificidade técnica e normativa. O fenômeno compreende, conforme o entendimento de Bruno Simma e Dirk Pulkowsky, uma tendência de especialização funcional da ordem jurídica internacional por meio da elaboração de normas especiais, que, por sua vez, afastam a aplicação das normas gerais de Direito Internacional, tais como as normas destinadas à responsabilização dos Estados. Assinalam os autores que "a característica principal dos regimes 'auto-suficientes' é a sua intenção de excluir totalmente a aplicação das sanções legais gerais de atos ilegais [...] em particular a aplicação de contramedidas por Estados prejudicados". (tradução nossa)..$^{15}$

As instâncias fragmentadas - cujos exemplos mais notórios são a Organização Mundial do Comércio, o Direito da Diplomacia e os diversos regimes de proteção aos Direitos Humanos - empregam racionalidades específicas, isto é, apresentam modus operandi voltados para a realização dos objetivos de cada regime. De acordo com Gunther Teubner:

\footnotetext{
${ }^{13}$ Buengenthal, apud, Flávia Piovesan. Direitos Humanos e Justiça Internacional: um estudo comparativo dos sistemas regionais europeu, interamericano e africano, p. 9.

${ }^{14}$ Henrique Weil Afonso. Unidade e Fragmentação do Direito Internacional: o papel dos Direitos Humanos como elemento unificador, 2009, p. 62.

15 "The principal characteristic of a self-contained regime is its intention to totally exclude the application of the general legal consequences of wrongful acts [...] in particular the application of countermeasures by an injured state." Bruno Simma; Dirk Pulkowsky. Of Planets and the Universe: Self-contained Regimes in International Law. European Journal of International Law, vol. 17, no. 3, p. 493.
} 
O novo direito do mundo é informado não por conjuntos de tradições e sim por uma auto-reprodução contínua de redes globais altamente técnicas, especializadas, por vezes organizadas e vagamente definidas, de natureza econômica, cultural, acadêmica ou tecnológica. (tradução nossa). ${ }^{16}$

William Burke-White ${ }^{17}$ enfatiza que o crescimento no número de normas criadas desde o fim da Segunda Guerra Mundial - originadas de tratados bilaterais e multilaterais - representa uma tendência da elevada densidade do Direito Internacional. Conforme destacado pelo autor, não apenas eleva-se o número de matérias disciplinadas, como também a intensidade desta regulação é objeto de transformação: "A criação de tantas novas obrigações legais sugere que áreas anteriormente abarcadas no alcance da política nacional estão passando por um processo de legalização" (tradução nossa). ${ }^{18}$

Não apenas no âmbito normativo, a ordem jurídica internacional se transforma: as últimas décadas também foram marcadas por uma proliferação de tribunais e cortes internacionais destinados à resolução de uma miríade de conflitos internacionais. Gunther Teubner e Andreas Fischer-Lescano ${ }^{19}$ contabilizam cerca de 125 instituições internacionais que se enquadram nos requisitos de tribunais ou cortes, isto é, instituições nas quais autoridades independentes proferem decisões de cunho legal:

Dentre outros, esta jurisdição internacional compreende a Corte Internacional de Justiça (CIJ), a Corte Internacional para o Direito do Mar, vários tribunais para reparações, cortes e tribunais penais internacionais, instâncias nacionais-internacionais híbridas, órgãos judiciais para comércio e investimento, tribunais regionais de direitos humanos e instituições derivadas de convenções, assim como outras cortes regionais, como a Corte Européia de Justiça [...]. (tradução nossa). ${ }^{20}$

\footnotetext{
16 "The new living law of the world is nourished not from stores of tradition but from the ongoing self-reproduction of highly technical, highly specialized, often formally organized and rather narrowly defined, global networks of an economic, cultural, academic or technological nature." Gunther Teubner. Global Bukowina: Legal Pluralism in the World Society. Global Law without a State, p. 5.

${ }^{17}$ William W. Burke-White, International Legal Pluralism, p.964.

18 "The creation of so many new legal obligations suggests that areas previously within the exclusive purview of national politics are becoming legalized."
}

${ }^{19}$ Gunther Teubner; Andreas Fischer-Lescano. Regime-collisions: the vain search for legal unity in the fragmentation of global law. Michigan Journal of International Law, Vol. 25, p. 1000.

20 "Amongst others, this international jurisdiction comprises the International Court of Justice (ICJ), the International Tribunal for the Law of the Sea, various tribunals for reparations, international criminal courts and tribunals, hybrid international-national tribunal instances, trade and investment judicial bodies, regional human rights tribunals and convention-derived institutions, as well as other regional courts, such as the European Court of Justice [...]".Gunther Teubner; Andreas Fischer-Lescano. Regime-collisions: the vain search for legal unity in the fragmentation of global law. Michigan Journal of International Law, Vol. 25, pp. 1000-1001. 
Em um contexto de rompimento com a unidade do Direito Internacional, a teoria voluntarista ${ }^{21}$ perde força, cedendo espaço a doutrinas que militam por uma conjugação de esforços de entidades não-estatais na governança da sociedade internacional, com impactos diretos na formatação do próprio Estado contemporâneo ${ }^{22}$. Relativizase, portanto, o princípio da soberania estatal em face do papel desempenhado por organizações internacionais e entidades supra-estatais no trato de questões globais, que irradiam conseqüências no nível do Estado-nação. Nesse sentido, adverte Gerhard Hafner que "[...] os Estados poderão lançar-se na atividade de fórum shopping, recorrendo ao mecanismo que melhor atenda a seus interesses" (Tradução nossa). ${ }^{23}$

Especialistas apontam para diversos problemas práticos resultantes da adoção da ótica da fragmentação. Eventuais conflitos advindos da superposição de jurisdições de diferentes tribunais representam um sério obstáculo à manutenção de uma configuração estável para a ordem jurídica internacional. Como conseqüência, as formas tradicionais de resolução de conflitos de normas parecem ser insuficientes diante da emergência desta ampla variedade de relações inter-racionais e inter-jurisdicionais, devendo os esforços se voltarem no âmbito do desenvolvimento de novos modos de superação de conflitos. ${ }^{24}$

A disputa por espaços normativos, com a conseqüente imposição de um modo de pensar único, erradia efeitos não apenas para o Direito Internacional: a autonomia de governos e poderes locais é reduzida, minando sua capacidade de responder às demandas por políticas adequadas às necessidades da população. ${ }^{25}$

\section{COMÉRCIO INTERNACIONAL E DIREITOS HUMANOS}

Os desafios advindos da abordagem fragmentária do Direito Internacional são

\footnotetext{
${ }^{21}$ Gerson de Britto de Mello Boson (1994) explica que a doutrina voluntarista repousa na idéia central de que o Estado soberano não se submete a nenhuma autoridade. Seu poder alcança a alcunha de 'poder jurídico' no momento em que a esta entidade abstrata se impõe voluntariamente a observância de uma obrigação internacional: "Esta limitação voluntária é uma manifestação de seu poder, pela qual o Estado demonstra ser livre" (BOSON. BH: Del Rey, 1994, p. 85).

${ }^{22}$ Neste particular, importante tendência vem se observando na questão da segurança doméstica. Rita Abrahamsen e Michael C. Williams (2007), em interessante estudo acerca da privatização da segurança pública na África do Sul, apontam para novas evoluções na questão do monopólio do uso da força pelo Estado e a participação de entidades não-estatais no desempenho desta função.

23 "[.... States may engage in forum shopping, resorting to the mechanisms that corresponds best to their state interests." Gerhard Hafner. Pros and Cons insuing from fragmentation of International Law. Michigan Journal of International Law, vol. 25, p. 857.
}

${ }^{24}$ William W. Burke-White. International Legal Pluralism, p. 1002.

${ }^{25}$ Mireille Delmas-Marty. Três Desafios para um Direito Mundial. RJ: Ed. Lumen Juris, 2003, p. 121. 
observados no cotidiano da prática legal em nível internacional, cujos efeitos repercutem para a formação de políticas públicas pelos poderes locais. A disputa comercial em sede da Organização Mundial do Comércio (OMC) envolvendo os Estados Unidos e o Brasil - centrado em torno da quebra de patentes por parte do governo brasileiro na produção de medicamentos para o tratamento da AIDS - consiste em um exemplo paradigmático desta nova realidade para o Direito Internacional, sendo, portanto, indispensável sua investigação.

O Artigo 68 da Lei de Patentes Brasileira (Lei no. 9279/96, que regula direitos e obrigações relativos à propriedade industrial) permite a produção doméstica de medicamentos por meio de cópias - os denominados medicamentos genéricos ${ }^{26}$ nos casos em que a população é ameaçada por determinada epidemia e os preços do medicamento no mercado mundial sejam excessivamente altos. O mesmo Artigo 68 estabelece a produção doméstica de medicamentos patenteados na hipótese de uma firma internacional que venha vendendo tais drogas por um período superior a três anos, contudo, sem estabelecer uma linha de produção no país.

O programa brasileiro de tratamento da AIDS consumiu, em 1997, cerca de trezentos milhões de dólares com a compra de medicamentos. Dois medicamentos apenas - o Efavirenz e o Nefinalvir - representavam um terço dessa despesa e eram patenteados pela multinacional norte-americana Merck e pela suíça Roche.

Uma vez que nem uma nem outra empresa estava engajada na produção dos medicamentos no Brasil, o Ministério da Saúde anunciou a produção genérica destes, por meio do mecanismo "licença compulsória". O governo norte-americano, em resposta, considerou tal ação potencialmente discriminatória para detentores de patentes deste país, vindo a solicitar consultas bilaterais perante a Organização Mundial de Comércio no ano 2001.27

Em princípio, a questão deveria ser tratada como mais um caso envolvendo uma pendência tipicamente comercial, passível de ser submetida à $\mathrm{OMC}$, conforme fizera os EUA. No entanto, um exame mais detido da controvérsia traz à tona diferentes modos de se conceber a disputa: (i) um conflito entre a lei brasileira de patentes e os direitos dos donos das patentes (empresas norte-americanas); (ii) um conflito entre a Organização Mundial do Comércio e a Organização Mundial de Saúde (OMS), isto é, uma disputa entre jurisdições diversas; (iii) e um conflito envolvendo diferentes racionalidades que competem pelo mesmo espaço normativo.

\footnotetext{
${ }^{26}$ Decreto no. 9787 , de 11 de fevereiro de 1999.

${ }^{27}$ World Trade Organization (WTO). 2001a. Dispute Settlement Body, Brazil - Measure Affecting Patent Protection - Request for Consultations by the United Stated, WTO Doc. WT/DS199/3, 9 Janeiro 2001.
} 
O referido embate, que em uma interpretação superficial seria enquadrado como tipicamente comercial, resultou na elaboração de uma Resolução por parte da Comissão de Direito Humanos da $\mathrm{ONU}^{28}$ no sentido da facilitação de acesso a medicamentos essenciais ao tratamento de pandemias - tal qual a AIDS - e de assegurar o direito dos Estados de promover melhores condições de vida aos seus cidadãos.

Também na esfera comercial, o conflito teve repercussões que exorbitam a racionalidade meramente econômica: em novembro de 2001, a Rodada Doha ${ }^{29}$ afirmou o compromisso da $\mathrm{OMC}^{30}$ na facilitação da implementação de medidas de proteção à saúde pública por parte dos Estados membros. A esse respeito, ponderam Gunther Teubner e Andreas Fisher-Lescano:

Medidas como a do programa brasileiro de AIDS devem, portanto, ser excetuadas da lógica econômica na medida em que o padrão normal de proteção às patentes não deve ser aplicado nestes casos. Os conflitos críticos seriam uma das colisões identificáveis entre normas de racionalidade econômica e normas formadas no contexto da proteção da saúde. (tradução nossa). ${ }^{31}$

Desse modo, constata-se a utilização de argumentos referentes à proteção a Direitos Humanos em sede de um órgão voltado para a resolução de disputas comerciais. Uma vez que "[...] não é mais possível resolver, por exemplo, questões referentes ao comércio de modo independente do problema da proteção ao meio am-

\footnotetext{
${ }^{28}$ United Nations Comission on Human Rights. Specific Groups and Individuals: Other Vulnerable Groups and Individuals, $5^{\text {th }}$ Session, Agenda Item 14(d), at 169, U.N. Doc. E/CN.4/2001/80.

${ }^{29}$ World Trade Organization (WTO). 2001b. Ministerial Conference. Ministerial Declaration, 4th Session, WT/ MIN(01)/Dec/1, parágrafo 17, 20 Novembro 2001.

${ }^{30}$ Também merece atenção a declaração da OMC quanto ao tema: "Nós enfatizamos a importância que conferimos à implementação e interpretação do Acordo de Comércio relativo a aspectos de Direitos de Propriedade Intelectual (Acordo TRIPS) de forma a apoiar a saúde pública, através de promoção tanto do acesso a medicamentos existentes e pesquisa quanto o desenvolvimento de novos medicamentos [...]" Tradução nossa. "We stress the importance we attach to implementation and interpretation of the Agreement on Trade-Related Aspects of Intellectual Property Rights (TRIPS Agreement) in a manner supportive of public health, by promoting both access to existing medicines and research and development into new medicines [...]". (WTO, 2001c).

31 "Measures such as the Brazilian AIDS program must thus be exempted from economic logic to the degree that the normal standard for patent protection is not to be applied in such cases. The critical conflict issue would thus be one of identifying collisions between the norms of economic rationality and norms formed within the context of the protection of health." Gunther Teubner; Andreas Fischer-Lescano. Regime-collisions: the vain search for legal unity in the fragmentation of global law. Michigan Journal of International Law, Vol. 25, p. 1032.
} 
biente ou a busca pelos direitos humanos" ${ }^{\prime 32}$, a bem-sucedida formulação de políticas públicas de saúde depende, em muitos casos, da prevalência de uma racionalidade que privilegie a realização de Direitos Humanos, afastando argumentos que possam desvirtuar a disputa e enquadrá-la na esfera de aplicação de normas de comércio internacional.

\section{CONCLUSÃO}

A força normativa e dissuasiva das variadas racionalidades atuantes no plano internacional mitigam o papel do Estado e reduzem o âmbito da aplicação das doutrinas tradicionais do Direito Internacional. Com especial relevância, o poder desempenhado pelos interesses políticos e econômicos de empresas e governos, elites, ideologias e discursos, cada vez mais sedutores, enfraquecem, fragilizam e colocam em xeque o potencial emancipador do Direito Internacional em um mundo cada vez mais complexo, onde interesses, muitas vezes conflitantes, almejam sucesso.

Entretanto, a crise das doutrinas tradicionais não deve ser vista de forma negativa. $\mathrm{O}$ aprendizado com a experiência fragmentária pode ensejar a construção de um novo sistema internacional. Conflitos como os analisados neste texto são reveladores da impossibilidade de se reduzir todas as questões a uma racionalidade meramente econômica e matematizada. O que pode ser analisado como crise pode ser, finalmente, compreendido como possibilidade de superação de um discurso ideológico que se tornou hegemônico nas ultimas décadas.

As transformações ocorrem a partir de conflitos que são reveladores de impossibilidades. A compreensão destas impossibilidades empurra os atores do jogo internacional, obrigatoriamente, para a construção de novas alternativas, que, no caso, exigem a construção de um novo sistema que seja capaz de religar saberes e discursos coerentes e integrais. A superação da redução do mundo a um mero discurso econômico, dessa forma, não surge apenas de construções e embates teóricos, mas de práticas políticas no espaço institucional fragmentado internacionalmente. O que se revela aí é o óbvio das práticas políticas: novas soluções surgem de novos problemas. Discutir essas questões, revelando impossibilidades ideológicas, irá gerar novas configurações para um mundo integrado que, pretendemos, seja justo.

\footnotetext{
32 Tradução nossa: "It is no longer possible to resolve, for example, trade questions de-linked from the problem of environmental protection of the pursuit of human rights. [...] What must be avoided, however, is this fragmentation leading to self-contained islands of international law, de-linked from other branches of international law."Joost Pauwelyn. Bridging Fragmentation and Unity: International Law as a universe of inter-connected islands. Michigan Journal of International Law, vol. 25, p. 904.
} 


\section{REFERÊNCIAS}

ABRAHAMSEN, Rita \& WILLIAMS, Michael C. Securing the City: Private Security Companies and Non-State Authority in Global Governance. International Relations, vol. 21, pp. 237-253, 2007.

AFONSO, Henrique Weil. Unidade e Fragmentação do Direito Internacional: o papel dos Direitos Humanos como elemento unificador. Revista Eletrônica de Direito Internacional, v. 4, pp. 53-90, 2009.

BOSON, Gerson de Britto Mello. Direito internacional público: o Estado em direito das gentes. Belo Horizonte: Del Rey, 1994.

BURKE-WHITE, William W. International Legal Pluralism. Michigan Journal of International Law, vol. 25, pp. 963-979, summer 2004.

BYERS, Michael. A Lei da Guerra: Direito Internacional e conflito armado. Rio de Janeiro: Ed. Record, 2007.

CANÇADO TRINDADE, Antônio Augusto. A Humanização do Direito Internacional. Belo Horizonte: Del Rey, 2006.

CLAUSEWITZ, Carl von. On War. London: Penguin Books, 1982.

CREVELD, Martin van. Ascensão e declínio do Estado. São Paulo: Martins Fontes, 2004.

DELMAS-MARTY, Mireille. Três Desafios para um Direito Mundial. Trad. Fauzi H. Choukr. Rio de Janeiro: Editora Lumen Juris, 2003.

FERRAJOLI, 2007, p. 50.

HAFNER, Gerhard. Pros and Cons insuing from fragmentation of International Law. Michigan Journal of International Law, vol. 25, pp. 849-863, summer 2004.

MAGALHÃES, José Luiz Quadros de. Identidades e identificações: da possibilidade de construção de uma ética universal. Veredas do Direito, vol. 5, no. 9/10, pp. 45-61, JaneiroDezembro de 2008 .

PAUWELYN, Joost. Bridging Fragmentation and Unity: International Law as a universe of inter-connected islands. Michigan Journal of International Law, vol. 25, pp. 903-916, summer 2004. 
Europe, America and the Unity of International Law. Março de 2006. Duke Law School Legal Studies Paper No. 103. Disponível em: <http://ssrn.com/abstract=893611> Acesso em 28 abril 2009.

PIOVESAN, Flávia. Direitos Humanos e Justiça Internacional: um estudo comparativo dos sistemas regionais europeu, interamericano e africano. São Paulo: Saraiva, 2006.

ROSENNE, Sh. Recueil des Cours. Tome 291 de La collection. The Hague: Martinus Nijhoff Publishers, 2002.

SANTOS, Boaventura de Souza. Uma concepção multicultural de direitos humanos. Lua Nova: Revista de Cultura e Política, vol. 39, p. 105-124, 1997.

SIMMA, Bruno; PULKOWSKY, Dirk. Of Planets and the Universe: Self-contained Regimes in International Law. European Journal of International Law, vol. 17, no. 3, pp. 483-529, 2006.

TEUBNER, Gunther. Global Bukowina: Legal Pluralism in the World Society. Global Law without a State. Brookfield: Dartmouth, pp. 3-28, 1997.

TEUBNER, Gunther; FISCHER-LESCANO, Andreas. Regime-collisions: the vain search for legal unity in the fragmentation of global law. Michigan Journal of International Law, Vol. 25, pp. 999-1045, summer 2004.

United Nations Comission on Human Rights. Specific Groups and Individuals: Other Vulnerable Groups and Individuals, $57^{\text {th }}$ Session, Agenda Item 14(d), at 169, U.N. Doc. E/CN.4/2001/80, 2000.

World Trade Organization (WTO). 2001a. Dispute Settlement Body, Brazil - Measure Affecting Patent Protection - Request for Consultations by the United Stated, WTO Doc. WT/ DS199/3, 9 Janeiro 2001.

World Trade Organization (WTO). 2001b. Ministerial Conference. Ministerial Declaration, 4th Session, WT/MIN(01)/Dec/1, parágrafo 17, 20 Novembro 2001.

World Trade Organization. (WTO). 2001c. Ministerial Conference. Declaration of the TRIPS Agreement and Public Health, WT/MIN(01)/DEC/2, 20 Novembro 2001. 